\title{
LA DIMENSIÓN IDEOLÓGICA DE LA UNIVERSIDAD INTERCULTURAL A TRAVÉS DEL DISCURSO Y LA PRÁCTICA. UNA PERSPECTIVA DESDE MÉXICO
}

por ZUZANA ERDÖSOVÁ

(Universidad Autónoma del Estado de México)

\begin{abstract}
Resumen
En el artículo se analiza el aspecto discursivo y práctico de la dimensión ideológica de la Universidad Intercultural, un modelo educativo mexicano creado en 2003 en reacción al reconocimiento constitucional de la diversidad cultural, representada por los pueblos indígenas. Con base en un trabajo de campo en dos Universidades Interculturales se concluye que la existencia del modelo educativo es motivada más que nada por la necesidad de fortalecer la posición ideológica neoindigenista del Estado mexicano.

Palabras claves: universidad; interculturalidad; pueblos indígenas; México
\end{abstract}

Discourse and practical aspects of the ideological dimension of the Intercultural University, a Mexican perspective

\begin{abstract}
The paper analyses the discourse and practical aspects of the ideological dimension of the Intercultural University, a Mexican educational model founded in 2003 in reaction to the constitutional recognition of the cultural diversity represented by the indigenous nations. Based on a field research in two different Intercultural Universities it is concluded that the educational model exists mostly to support of the neoindigenist ideological position of the Mexican state.
\end{abstract}

Keywords: university; interculturality; indigenous peoples; Mexico

\section{Introducción}

Dentro de Latinoamérica, México es un emisor importante del discurso interculturalista. Desde la primera mitad del siglo XX, el país ha sido el líder latinoamericano en la materia de la educación dirigida a los grupos étnicos indígenas y ha atravesado por tres etapas educativas importantes: las modalidades educativas bilingües de transición al castellano, la Educación Bicultural Bilingüe y, desde los años 90, la Educación Intercultural Bilingüe. Esta última está culminando en la actualidad con la política educativa mexicana llamada "Universidad Intercultural".

Dicha Universidad Intercultural es un modelo educativo reciente creado en el marco del Plan Nacional de Educación del gobierno del presidente Vicente Fox (2000-2006). Las primeras dos Universidades Interculturales fueron construidas en el Estado de México y en Chiapas, las mismas que se analizan en este artículo, sin embargo, hasta la fecha han sido construidas otras diez en diferentes partes del país. 
La Universidad Intercultural tiene una justificación política relevante: reacciona a la nueva orientación del Estado mexicano que en los años 90 reconoció constitucionalmente la diversidad cultural que define México. Bajo ésta se entiende básicamente el carácter pluriétnico del país, el que hoy alberga alrededor de sesenta grupos étnicos originarios, descendientes de los pueblos precolombinos tras cinco siglos de hibridización, sincretismo y mestizaje. La pretensión del Estado mexicano es gestionar esta diversidad cultural bajo el lema intercultural, tan en boga en los discursos educativos actuales, de tal modo que la Universidad Intercultural involucra también a la sociedad no indígena para evitar la acusación de tendencias segregacionistas.

Este contexto no es libre de conflicto. Al inicio del sexenio, el gobierno de Vicente Fox aparentaba una supuesta simpatía hacia las demandas autonómicas indígenas (incluyendo las del Ejército Zapatista de Liberación Nacional, EZLN), sin embargo, tras el rechazo de la autonomía indígena como reforma constitucional, las negociaciones entre los pueblos originarios y el Estado mexicano fueron perdidas a favor de un sistema neoindigenista vertical y paternalista, llevado a cabo con un discurso oficial renovado (interculturalista) y con la mera asistencia de consultores indígenas. ${ }^{1}$ De tal modo que la institucionalización de la propuesta del modelo de la Universidad Intercultural se dio en un ambiente donde las decisiones no habían sido basadas en la academia, sino en "(...) una perspectiva gubernamental que buscaba generar una propuesta 'suave' que no impactara de manera decidida en los problemas de fondo de las comunidades indígenas (...)".2

Casi 15 años después, diversos estudios recientes revelan el desencanto por estas instituciones educativas. Aunque, como se había señalado, la implementación del modelo educativo haya transcurrido de manera casi completamente unilateral desde el gobierno federal, los primeros rectores de las primeras dos universidades de este tipo sí fueron antropólogos expertos con una amplia visión decolonial (Felipe González Ortiz en la Universidad Intercultural del Estado de México, UIEM, y Andrés Fábregas Puig en la Universidad Intercultural de Chiapas, UNICH). Estos personajes supieron entender y aprovechar en la práctica el potencial del nuevo modelo universitario, y darle un rumbo prometedor. Sin embargo, después de este corto período inicial comenzó la fase de decaimiento y las Universidades Interculturales, desde su fundación vistas por muchos como instituciones educativas de segunda, se han ido convirtiendo en depósitos para personae non gratae, generalmente políticos estatales. Los fenómenos negativos que acompañan este proceso son varios.

Por un lado, en términos epistémicos, se nota la paulatina transformación del modelo educativo intercultural hacia el modelo universitario convencional y hegemónico, jerárquico y vertical, con rumbo occidentalizante. Señalemos, por ejemplo, la controversia en la UNICH en 2014 en torno a la aplicación del modelo por

1 Genner LLANES ORTIZ, "Interculturalización fallida. Desarrollismo, neoindigenismo y Universidad Intercultural en Yucatán, México", Trace 53, 2008, [consultado 20 de septiembre de 2010], accesible de: http://trace.revues.org/index390.html

2 León Enrique ÁVILA ROMERO - Alberto BETANCOURT POSADA - Gabriela ARIAS HERNÁNDEZ - Agustín ÁVILA ROMERO, "Vinculación comunitaria y diálogo de saberes en la educación superior intercultural en México”, RMIE 70 (21), 2016, pp. 759-783. 
competencias, generalizado en el resto del sistema educativo mexicano. En la actualidad, crece el desconocimiento y desinterés por el modelo educativo intercultural, por lo cual las Universidades Interculturales sirven como simples transmisoras de la pegagogía convencional, en vez de mediar entre el mundo indígena y la ciencia occidental. ${ }^{3}$

Por otro lado, las Universidades Interculturales están siendo aprovechadas y controladas por los grupos de poder de los estados respectivos, a pesar de ser financiadas, en gran parte, por el gobierno federal ${ }^{4}$ (como se nota, por ejemplo, en la UIEM con relación al Partido Revolucionario Institucional, PRI). Este proceso significa la politización de los espacios académicos, acompañada con diversas situaciones de fragmentación y descomposición interna causada por las diferencias partidistas y luchas sindicales (muy marcada, por ejemplo, en el caso de la UNICH desde la rectoría de Javier Álvarez Ramos).

Ahora bien, regresando al concepto de la interculturalidad, por las razones recién expuestas, éste dista de ser académica y políticamente neutral, aunque el discurso interculturalista, oficializado en muchos países latinoamericanos, tiende a recibirse acríticamente. Para las instancias gubernamentales, hablar institucionalmente de la interculturalidad a menudo equivale a practicarla. Además, las definiciones de la interculturalidad varían según los intereses del que esté empleando el concepto. Por ejemplo, algunos sectores de las sociedades latinoamericanas, generalmente los movimientos generados por los grupos étnicos que viven en condiciones de marginación social, suelen utilizar el concepto de la interculturalidad en relación con sus demandas por los derechos colectivos. Por eso, la problemática tanto conceptual como práctica de la interculturalidad en Latinoamérica últimamente ha adquirido una dimensión bastante compleja, y para entender los aportes de las políticas educativas que se encuentran respaldadas por este concepto se hace indispensable analizarlas de manera crítica no sólo desde el enfoque educativo centrado en los procesos de enseñanza, sino sobre todo desde el ideológico.

El debate sobre estos asuntos se encuentra delimitado por una serie de corrientes de pensamiento. En un extremo se sitúa el indigenismo y su versión "actualizada", el neoindigenismo. En México, el indigenismo moderno es una ideología posrevolucionaria basada en la aculturación de los pueblos indígenas para su integración a la Nación mediante el mestizaje. Este proyecto nacional entró en crisis al inicio de los años 80 del siglo XX cuando México adquirió la orientación neoliberal y se sumergió en los procesos globalizadores, pero no ha dejado de existir. En la actualidad se perpetúa en forma de la ideología "neoindigenista"5 que mantiene la antigua actitud paternalista y asistencialista hacia los culturalmente "otros", aunque ya no habla de la asimilación cultural directa sino, de manera más sofisticada, del "desarrollo de

3 Agustín ÁVILA ROMERO - León Enrique ÁVILA ROMERO, "Las universidades interculturales de México en la encrucijada”, Nóesis 50 (25), 2016, pp. 200-215.

4 Agustín ÁVILA ROMERO - León Enrique ÁVILA ROMERO, "El asalto a la interculturalidad: las universidades interculturales de México", Diversa 76 (27), 2014, pp. 37-54.

5 La terminología se retoma de Leif KORSBAEK - Miguel Ángel SÁMANO RENTERÍA, "El indigenismo en México. Antecedentes y actualidad”, Ra Ximhai 1 (3), México 2007, pp. 195-224. 
los pueblos indígenas". Éstos son vistos como entes marginados y no participantes en los beneficios de la civilización moderna.

En el ámbito nacional mexicano, el producto del pensamiento neoindigenista es precisamente el modelo educativo de la Universidad Intercultural. No es un hecho casual que dicho modelo esté enmarcado en el subsistema intercultural que ha sido creado, recientemente, dentro del sistema de la educación superior mexicana. ${ }^{6} \mathrm{La}$ Universidad Intercultural se caracteriza por insistir en que el Estado funja como el "proveedor de los servicios educativos" dirigidos a los grupos étnicos, esquivando las reivindicaciones de algunos de estos grupos por el derecho a gestionar la educación comunitaria desde las culturas originarias mismas.

En el otro extremo del eje ideológico se encuentran las cosmovisiones propiamente originarias que producen ideologías holísticas y alternativas a la epistemología occidental, tales como el llamado "Buen Vivir" (Sumak Kawsay o Suma Qamaña) en Ecuador y Bolivia. Además, dentro de la tradición intelectual occidental han surgido corrientes de pensamiento llamadas "poscoloniales" que en sus diferentes vertientes (Asia, África, Latinoamérica) representan una teoría crítica que pone al descubierto la dimensión colonial de la expansión capitalista, entendida no solamente en términos económicos, sino fundamentalmente culturales. El objetivo de esta teoría es formular un pensamiento emancipador, es decir, en vez de utilizar las teorías procedentes del Occidente para explicar el pensamiento occidental, se trata de abrir espacio a las reflexiones que se han hecho sobre este mismo desde otras lógicas culturales. ${ }^{7}$ La perspectiva poscolonial resulta útil para esclarecer el papel social de la Universidad Intercultural en México, ya que permite abordarla desde una serie de conceptos nuevos, tales como la "colonialidad del saber", construidos para otorgar debida importancia a los contextos interétnicos marcados por las relaciones de poder.

Hoy en día, los mecanismos del conocimiento hegemónicos ligados a la modernidad, tal como está entendida desde el Occidente, han reducido a los culturalmente "otros" en objetos de estudio, impidiendo que se comprendan a sí mismos y desterrando a los modos alternativos del saber de las fronteras de conocimiento. ${ }^{8}$ En estos términos, la teoría poscolonial habla acerca de la asimetría entre los diferentes tipos de conocimiento y propone avanzar hacia el llamado "diálogo de saberes" (subrayemos que este último término es altamente explotado en la teoría educativa de la Universidad Intercultural). A los que argumentan que el diálogo de saberes ya se ha hecho posible en las diferentes latitudes gracias a las políticas inter y multiculturales, hay que advertir que la visibilización de los saberes de los "otros" debe darse sin la tradicional actitud rescatista y esencialista hacia la cultura. ${ }^{9}$

6 El modelo educativo es gestionado por la Coordinación General de la Educación Intercultural Bilingüe, CGEIB, organismo de la Secretaría de Educación Pública, SEP.

7 Yolanda PARRA, "Para una pedagogía del Buen Vivir. Más allá del Océano: otros horizontes pedagógicos posibles,” in: Stefano SARTORELLO - León ÁVILA - Agustín ÁVILA (coords.), El Buen Vivir: Miradas desde adentro de Chiapas, San Cristóbal de las Casas 2012, pp. 164-196.

8 Aprender en sabiduría y el Buen Vivir, Quito 2004, p. 164.

9 Santiago CASTRO-GÓMEZ - Ramón GROSFOGUEL, "Giro decolonial, teoría crítica y pensamiento heterárquico", in: Santiago Castro-Gómez - Ramón Grosfoguel (comps.), El giro decolonial: reflexiones para una diversidad epistémica más allá del capitalismo global, Bogotá 2007, pp. 9-24. 
En el marco de lo anterior, en el presente trabajo se analiza el aspecto tanto discursivo como práctico del manejo de la interculturalidad por la Universidad Intercultural en relación con su potencial de generar cierto tipo de impacto social.

Los resultados mostrados a continuación desprenden de datos cualitativos que fueron recogidos mediante un trabajo de campo efectuado en dos Universidades Interculturales situadas en dos entidades federativas diferentes: la Universidad Intercultural del Estado de México (UIEM) y la Universidad Intercultural de Chiapas (UNICH). Se emplearon las siguientes técnicas concretas: la investigación bibliográfica, el análisis discursivo de la teoría educativa de la Universidad Intercultural y la recolección y análisis de los testimonios personales en forma de entrevistas a profundidad, ${ }^{10}$ las que fueron procesadas y analizadas mediante la técnica de la codificación y etiquetado. La estrategia metodológica fue acudir principalmente con los egresados de ambas Universidades y complementar esta información por la visión oficial proporcionada por una gama de actores institucionales (funcionarios y personal académico). Cabe resaltar que las experiencias personales de los licenciados formados por las Universidades Interculturales representan un punto de vista poco investigado hasta la fecha, sin embargo, cuyo potencial es indiscutible. Sus testimonios permiten aproximarnos a la actuación social (tanto a su concepción intelectual como a las prácticas reales) de este nuevo tipo de profesionista sobre el cual recae la difícil tarea de ir remediando la compleja situación interétnica de México. Por su parte, los puntos de vista de los actores institucionales complementan oportunamente los de los egresados, ya que generalmente contienen una visión oficial(ista) que deja al descubierto los planteamientos ideológicos claves del modelo educativo de la Universidad Intercultural.

\section{Pensar la interculturalidad: el concepto en el discurso}

El concepto de la interculturalidad es la piedra angular de la teoría educativa de la Universidad Intercultural mexicana, ya que en ésta se plantea la necesidad de formar un nuevo tipo de ciudadano que tenga cualidades "interculturales". Esto significa que debe tener sensibilidad hacia la problemática de la diversidad cultural y que debe ser un científico comprometido con el desarrollo tanto de su localidad de procedencia como el del México entero, proyectando la riqueza de su cultura al resto de la sociedad. ${ }^{11}$ Por eso, analizar cómo se cultiva dicha sensibilidad hacia la diversidad cultural en la UNICH y la UIEM fue el primer paso lógico para entender el papel social del modelo educativo analizado. Esta problemática se desdobla en

10 Se realizaron 28 entrevistas a profundidad: 21 con los egresados y 7 con el personal académico de la UNICH y la UIEM. Entre los egresados, 5 son hablantes de lenguas indígenas (HLI) con diferentes grados de bilingüismo en la lengua tzotzil, tzeltal, mazahua y castellano, 8 viven en hogares donde en las generaciones anteriores se hablaba alguna lengua indígena, aunque ellos mismos ya no la dominan, y 7 proceden de familias sin raíces culturales indígenas identificables. El personal administrativo/académico entrevistado incluye a los rectores de ambas Universidades y a los profesores encargados de impartir y gestionar las asignaturas que implican el trabajo de campo en las comunidades locales (la llamada Vinculación con la Comunidad).

11 María CASILLAS MUÑOZ - Laura SANTINI VILLAR, Universidad intercultural: un modelo educativo, México 2006, pp. 145-147. 
dos aspectos: la interculturalidad como un concepto que primero hay que entender para poder llevarlo a la práctica, y luego la aplicación misma.

En cuanto al primer aspecto, lo primero que llama la atención es la manera asistemática y a veces deficiente de explicar el significado del concepto de la interculturalidad a los alumnos de la UNICH y la UIEM. Es decir, no existe un manejo consistente de este concepto, importantísimo para el modelo educativo analizado, dentro de la comunidad académica. A una cuarta parte de los egresados entrevistados nunca les dieron ninguna definición de lo que significa la interculturalidad y una buena parte de los que sí recibieron una explicación señalan que permanecen con dudas. Tanto en la UNICH como en la UIEM, hay profesores quienes son conscientes de que el concepto académico de la interculturalidad no tiene una definición única, pero también hay docentes quienes se apegan a la ideología intercultural presente en el modelo educativo y, por último, hay profesores que no se orientan en la problemática intercultural e ignoran las dimensiones del concepto. Por supuesto, todas estas aproximaciones se reflejan en el alumnado; algunos estudiantes se apegan a una sola definición de la interculturalidad, otros no disponen de ninguna y todavía otros generan definiciones individuales gracias al esfuerzo propio, no tanto por la intervención de su alma mater.

En los entrevistados que sí proporcionaron una definición se nota una fuerte influencia de la ideología educativa de la Universidad Intercultural; resaltan el respeto por la diferencia, la necesidad de convivencia y el diálogo equitativo entre culturas como los elementos constitutivos de la interculturalidad. ${ }^{12}$ Como se puede observar, el modelo educativo conceptualiza la interculturalidad de una manera políticamente conveniente, puesto que esquiva el potencial latente conflictivo de cada contacto entrecultural, favorece la visión utópica de una sociedad pacífica y armónica, y no presta mayor atención a las relaciones de poder imperantes entre los grupos culturales en contacto. De manera que consideramos que la teoría educativa de la Universidad Intercultural no representa un instrumento eficaz para el análisis crítico de los problemas interétnicos del México actual.

Como consecuencia lógica de lo anterior, una gran parte de los actores involucrados en las Universidades Interculturales, incluyendo a los egresados, parecen confiar demasiado en la fuerza del concepto de la interculturalidad, colocando sobre él la responsabilidad de remediar algunos de los problemas más sensibles que vive la sociedad mexicana actual.

Es precisamente donde la interculturalidad entra en el juego de poderes y rige el carácter del "diálogo de saberes" que, con base en la teoría educativa, está orientado a "hacer compatibles los procesos de estudio, análisis y generación de nuevos conocimientos que beneficien a las poblaciones que las sustentan, y contribuya a librar

12 1) "La interculturalidad, nosotros la entendemos como primero el reconocimiento de la diversidad existente, entendida, además, como un derecho, el poder ser como soy. Pero al mismo tiempo, la interculturalidad la entendemos como el privilegio del diálogo, como el instrumento básico entre diferentes para construir acuerdos. Y como objetivo central, el que vivamos en armonía" (entrevista, rector, UNICH), 2) "Yo creo que la interculturalidad es englobar, convivir con nuestras diferencias, convivir sanamente, porque de esto se trata, que haya un clima ameno entre cosas diferentes, personas diferentes, tradiciones diferentes, y el respeto mutuo" (entrevista UNICH-05-S, egresado tzotzil). 
barreras de comunicación entre el conocimiento práctico y místico acumulado en la sabiduría indígena y el conocimiento científico generado en las universidades convencionales" ${ }^{13}$ Tanto en la teoría educativa como en las prácticas académicas, este diálogo de saberes prioriza el prisma científico moderno ante el conocimiento tradicional "práctico y místico" de los pueblos originarios (como la teoría lo califica). Se trata de una especie de mestizaje epistémico selectivo que favorece el desarrollo económico entendido desde la óptica de la modernidad, con la participación de sólo algunos elementos retomados de las culturas originarias que se ven oportunos para elevar la competitividad de los grupos indígenas en el mercado globalizado. En este contexto de la colonialidad del saber, no sorprende que la participación indígena en la construcción de las Universidades Interculturales y su influencia conceptual sobre la enseñanza sean mínimas.

\section{¿Vivir la interculturalidad? Del concepto a la práctica}

Si avanzamos hacia el análisis de las prácticas derivadas del concepto de la interculturalidad, lo primero que observamos es el hecho de que la teoría interculturalista (aun con todos los defectos señalados) no produce prácticas correspondientes. Esto se debe, en gran medida, a la ausencia de una metodología "intercultural" funcional que asuman y apliquen los educadores. No obstante, debería ser el primer pendiente de cada Universidad Intercultural elaborar métodos enraizados en la situación local que permitan gestionar la diversidad cultural, tomar decisiones conjuntas, resolver conflictos, dialogar y negociar eficientemente con los considerados como "diferentes". Además, tal metodología no debería emplearse sólo en los grupos de clase sino también en los procesos de investigación e implementación de los proyectos en las comunidades locales impulsados desde la Universidad Intercultural.

En cuanto a la perspectiva de los egresados, la mayoría de ellos obviamente nota diferencias significativas entre la convivencia "intercultural" transcurrida en los ámbitos de la UNICH y la UIEM y la situación en las universidades convencionales, donde la problemática étnica del alumnado no es el tema de mayor importancia. En ocasiones, los egresados mencionan detalles cotidianos como son los malentendidos o choques que se generan debido a la variedad cultural e lingüística dentro de los grupos de clase. En estas situaciones, se nota que la convivencia en el marco de una comunidad universitaria culturalmente diversa conlleva cierto estrés emocional, al menos al inicio, pero que tiende a estabilizarse con el tiempo y se convierte en una fuente significativa de aprendizaje entre los que se consideran mutuamente como "diferentes".

Hay que destacar que las visiones más escépticas sobre la calidad de la convivencia intercultural proceden de los informantes que más discrepan, culturalmente hablando, de la sociedad mayoritaria: los egresados de la UNICH con identidades indígenas. ${ }^{14}$ Pero tampoco faltan experiencias parecidas por parte de los egresados hispanohablantes de raíz urbana y/o mestiza; tanto en la UNICH como en la UIEM

13 CASILLAS - SANTINI, Universidad intercultural, p. 34.

14 "Inmediatamente, cuando hacíamos trabajos en equipo, nos hacíamos el grupo de los tzotziles. Y siempre había comunicación entre la misma identidad. Y el profesor se daba cuenta de eso, que tal 
se documentaron situaciones en las que se invierte el esquema dentro del cual los "indígenas" son los tradicionalmente discriminados por la sociedad mayoritaria, de tal modo que ahora los perjudicados son los "mestizos". ${ }^{15}$ Ambas perspectivas mencionadas ponen en tela de juicio la calidad de la intermediación intercultural de la UNICH y la UIEM.

El proceso definido por las prácticas interculturales puede resumirse como sigue. La UNICH y la UIEM proporcionan ámbitos abiertos a las alteridades culturales y al mismo tiempo van fomentando un juego de valores interculturales que tienen el potencial de transformar positivamente las actitudes e identidades personales, las que, por su parte, pueden reforzar la calidad de la convivencia en los ámbitos universitarios. Estos mecanismos funcionan en algunos casos pero fallan en otros, sobre todo cuando se aplican a jóvenes cuya experiencia vital complicada (barrera lingüística, discriminación, marginación, bajos ingresos) amortigua el entusiasmo ingenuo por la "convivencia pacífica entre las culturas" contenida en el concepto oficial de la interculturalidad. ${ }^{16}$ En fin, en los ámbitos académicos interculturales existen condiciones reales de asimetría e inequidad que las Universidades Interculturales difícilmente pueden resolver mediante los mecanismos usados en la actualidad. ${ }^{17}$

Pero a pesar de las imperfecciones ubicadas, tampoco se puede negar que los ámbitos universitarios culturalmente diversos por sí mismos actúan de manera enriquecedora sobre las experiencias de los alumnos. De tal modo que surgen complejos procesos identitarios en cuyo marco, en numerosos casos, se reorientan positivamente las actitudes hacia la procedencia étnica originaria propia y la diversidad cultural en general. Esto representa uno de los indiscutibles logros prácticos de la UNICH y la UIEM, aunque dichos logros se refieran a giros valorativos meramente individuales.

Se puede concluir este apartado señalando que la Universidad Intercultural mexicana atiende a los jóvenes (sobre todo indígenas) desde el imaginario occidental moderno y el sistema hegemónico del saber y, aunque en ocasiones pueda aparentarlo, de ningún modo proporciona espacio para la actuación autónoma de los pueblos originarios sobre la formación de su propia juventud.

vez se pueda romper y armar otras estrategias de trabajo para que de alguna forma se pueda llevar a cabo la famosa interculturalidad" (Entrevista UNICH-07-J, egresado tzotzil).

15 "Muchos nos criticaban esta parte de que éramos mestizos, ¿qué teníamos que estar haciendo en las comunidades originarias, hablantes, si nosotros estábamos con otra percepción cultural?" (Entrevista UNICH-04-E, egresado mestizo).

16 "Veía a los demás con buena ropa y dije: Con ellos creo que no ahorita, no sé si me voy a llevar porque algunos llevan carro y yo llegaba en bici o en pie [sic]. Con ellos no sé si pueda tratarme" (Entrevista UNICH-07-J, egresado tzotzil).

17 Paola ORTELLI - Stefano SARTORELLO, "Jóvenes universitarios y conflicto intercultural. Estudiantes indígenas y mestizos en San Cristóbal de Las Casas, Chiapas”, Perfiles Educativos No. especial XXXIII, México 2011, pp. 115-128. 


\section{El potencial social de los "licenciados interculturales"}

El "licenciado intercultural", o sea, el egresado de alguna licenciatura (pregrado) proporcionada por alguna Universidad Intercultural, es una figura llena de controversias. Entre todos los actores entrevistados existe la conciencia de que dentro de las licenciaturas interculturales ${ }^{18}$ deben formarse profesionistas diferentes a los "convencionales", pero falta consenso si los egresados de carne y hueso realmente cumplen con esta característica. De esta manera, la retórica interculturalista tiene que enfrentar el alcance limitado del concepto de la interculturalidad que ofrece a los profesores y alumnos de la UNICH y la UIEM; existe cierta incompatibilidad entre la formación profesional alternativa de los egresados interculturales y el mercado existente que impone sus exigencias ligadas sobre todo a la competitividad en áreas de oportunidad mayoritarias y fijamente establecidas.

Si los profesionistas interculturales son competitivos o no depende del trabajo que desempeñen: los que trabajan en áreas previstas por sus perfiles de egreso ${ }^{19}$ traen habilidades alternativas que resultan rentables y útiles, tales como diferentes grados de competencia en las lenguas originarias, capacidad de moverse en los ámbitos comunitarios, de entablar cooperación funcional con la gente local y plantear propuestas de proyectos que deberían ser compatibles con sus necesidades verdaderas. Pero si en sus puestos de trabajos reales se alejan de estos perfiles de egreso, su potencial competitivo se reduce significativamente. Así llegamos a la siguiente paradoja: se supone que los egresados interculturales no deben competir con los convencionales, sino buscar un nicho propio y alternativo donde desempeñarse (los ámbitos comunitarios, de preferencia). Pero en la práctica, muchos cuestionan que esto sea posible y declaran verse bajo la presión constante de competir con sus contrapartes no interculturales. ${ }^{20}$ Además, la burocracia inherente a la administración de las Universidades Interculturales "subsume las iniciativas creativas e innovadoras de los jóvenes que buscan su reafirmación cultural y el respeto a la diversidad biocultural del mundo". ${ }^{21}$

En cuanto al potencial social del nuevo profesionista intercultural, el impacto que la UNICH y la UIEM son capaces de generar, se da a través de las actuaciones, por cierto, más individuales que colectivas, de sus egresados. Al respecto, muchos de éstos reconocen que la formación intercultural transformó su modo de ser y pensar. ${ }^{22}$ Generalmente expresan solidaridad con las comunidades locales (sobre

18 En el momento en que se realizó el trabajo de campo, la UIEM y la UNICH proporcionaban las siguientes licenciaturas: Turismo Alternativo, Comunicación Intercultural, Lengua y Cultura y Desarrollo Sustentable.

19 Todos los 11 egresados entrevistados de la UNICH trabajan en menor o mayor medida dentro de sus perfiles. Esto sucede sólo con 4 de los 10 egresados de la UIEM.

20 "Nosotros como egresados, no sé si nos llegaba la melancolía (...) De globalidad nos decían: ¿Cómo vas a competir contra chavos de la UNAM (Universidad Autónoma de México), chavos del Poli (Politécnico)?" (entrevista UIEM-02-I, egresado de origen mestizo).

21 Agustín ÁVILA ROMERO - León Enrique ÁVILA ROMERO, "El asalto a la interculturalidad: las universidades interculturales de México", Diversa 76 (27), 2014, pp. 37-54.

22 "La visión que nosotros tenemos al salir que no es de economistas, no es de perseguir un lucro en todas partes o verle cara de dinero a todo. A nosotros lo que nos interesa es poder ayudar" (entrevista UNICH-02-G, egresada mestiza). 
todo en el caso de los alumnos de origen indígena) y en su mayoría les atrae seguir haciendo el trabajo de campo donde, sin embargo, entra la divergencia entre la vocación personal y las exigencias de la vida real, debido a la cual muchas aspiraciones de este tipo se relegan hacia el futuro a veces más, a veces menos probable. De tal modo que las Universidades Interculturales hacen egresar a personas que en muchos casos traen un considerable potencial social pero que quedan desaprovechadas por la sociedad debido a lo difícil que resulta colocarse en un puesto laboral que sea compatible con sus perfiles de egreso. Para referencia más detallada sobre la muestra, en la siguiente tabla se puede consultar la síntesis de la situación laboral de los egresados entrevistados.

Tab. 1 Congruencia entre el perfil de egreso y el trabajo actual de los egresados de la UNICH y UIEM. Síntesis.

\begin{tabular}{|l|l|l|l|l|}
\hline \multicolumn{3}{|c}{ SÍNTESIS: CONGRUENCIA PERFIL DE EGRESO/TRABAJO } \\
\hline $\begin{array}{l}\text { Egresad@ / } \\
\text { Licenciatura }\end{array}$ & $\begin{array}{l}\text { Tiene } \\
\text { empleo }\end{array}$ & $\begin{array}{l}\text { Trabaja } \\
\text { dentro } \\
\text { del perfil }\end{array}$ & $\begin{array}{l}\text { Hace trabajo de } \\
\text { campo en ámbitos } \\
\text { comunitarios }\end{array}$ & $\begin{array}{l}\text { Percibe dife- } \\
\text { rencia siendo } \\
\text { egresado } \\
\text { intercultural }\end{array}$ \\
\hline $\begin{array}{l}\text { UNICH-01-T } \\
\text { Turismo Alternativo }\end{array}$ & Sí & Sí & $\begin{array}{l}\text { Ahora no, } \\
\text { en el futuro } \\
\text { probablemente sí }\end{array}$ & Sí \\
\hline $\begin{array}{l}\text { UNICH-02-G } \\
\text { Turismo Alternativo }\end{array}$ & Sí & Sí & $\begin{array}{l}\text { Ahora no, } \\
\text { en el futuro } \\
\text { probablemente sí }\end{array}$ & Sí \\
\hline $\begin{array}{l}\text { UNICH-03-D } \\
\text { Turismo Alternativo }\end{array}$ & Sí & Sí & Sí & Sí \\
\hline $\begin{array}{l}\text { UNICH-04-E } \\
\text { Turismo Alternativo }\end{array}$ & Sí & Sí & Sí & Sí \\
\hline $\begin{array}{l}\text { UNICH-05-S } \\
\text { Turismo Alternativo }\end{array}$ & Sí & Sí & $\begin{array}{l}\text { Ahora no, en el } \\
\text { futuro es posible } \\
\text { que sí }\end{array}$ & Parcialmente \\
\hline $\begin{array}{l}\text { UNICH-06-M } \\
\text { Turismo Alternativo }\end{array}$ & Sí & Sí & Sí & Parcialmente \\
\hline $\begin{array}{l}\text { UNICH-07-J } \\
\text { Turismo Alternativo }\end{array}$ & Sí & Sí & Sí & Sí \\
\hline $\begin{array}{l}\text { UNICH-08-S } \\
\text { Comunicación Intercultural }\end{array}$ & Sí & Sí & Sí & Aho \\
\hline $\begin{array}{l}\text { UNICH-09-A } \\
\text { Comunicación Intercultural } \\
\text { Comunicación Intercultural }\end{array}$ & Sí ní en el & Parcialmente \\
\hline ComunicH-11-F & Sí & Sí & - \\
\hline
\end{tabular}




\begin{tabular}{|l|l|l|l|l|}
\hline $\begin{array}{l}\text { UIEM-01-E } \\
\text { Comunicación Intercultural }\end{array}$ & Sí & $\begin{array}{l}\text { Sí, pero sin } \\
\text { enfoque } \\
\text { intercultural }\end{array}$ & No & Sí \\
\hline $\begin{array}{l}\text { UIEM-02-I } \\
\text { Comunicación Intercultural }\end{array}$ & Sí & Sí & Sí & Sí \\
\hline $\begin{array}{l}\text { UIEM-03-N } \\
\text { Comunicación Intercultural }\end{array}$ & Sí & No & $\begin{array}{l}\text { No, pero le } \\
\text { gustaría }\end{array}$ & Sí \\
\hline $\begin{array}{l}\text { UIEM-04-Y } \\
\text { Comunicación Intercultural }\end{array}$ & Sí & No & $\begin{array}{l}\text { No, pero le } \\
\text { gustaría }\end{array}$ & Sí \\
\hline $\begin{array}{l}\text { UIEM-05-R } \\
\text { Comunicación Intercultural }\end{array}$ & Sí & $\begin{array}{l}\text { Sí, pero sin } \\
\text { enfoque } \\
\text { intercultural }\end{array}$ & $\begin{array}{l}\text { Ahora no, hace } \\
\text { poco sí, le gustaría } \\
\text { hacerlo de nuevo }\end{array}$ & Sí \\
\hline $\begin{array}{l}\text { UIEM-06-G } \\
\text { Comunicación Intercultural }\end{array}$ & No & No trabaja & $\begin{array}{l}\text { No, pero le } \\
\text { gustaría }\end{array}$ & Sí \\
\hline $\begin{array}{l}\text { UIEM-07-J } \\
\text { Comunicación Intercultural }\end{array}$ & Sí & Sí & Sí & No \\
\hline $\begin{array}{l}\text { UIEM-08-Al } \\
\text { Desarrollo Sustentable }\end{array}$ & Sí & Sí & Sí & Sí \\
\hline $\begin{array}{l}\text { UIEM-09-A } \\
\text { Desarrollo Sustentable }\end{array}$ & Sí & No & $\begin{array}{l}\text { No, pero le } \\
\text { gustaría }\end{array}$ & No \\
\hline $\begin{array}{l}\text { UIEM-10-Gr } \\
\text { Lengua y Cultura }\end{array}$ & Sí & Sí & Sí \\
\hline
\end{tabular}

En un plano más general, la formación de los profesionistas interculturales adquiere importancia a través de la ideología educativa que une el proyecto de la Universidad Intercultural con la orientación ideológica y política neoindigenista del Estado mexicano actual. La formación universitaria intercultural apoya o crea en los alumnos ideas novedosas sobre el papel que deben desempeñar en la sociedad para que ésta "mejore". Bajo la mejora, entendida ante todo como el desarrollo económico y cultural en las comunidades indígenas y rurales, y la promoción de un estilo de vida sustentable y ecológico, generalmente subyacen prioridades, valores y criterios modernos: pensamiento empresarial, competitividad, idea del "rescate" cultural unilateral o el compromiso institucional paternalista con las comunidades marginadas. La mayoría casi absoluta de los funcionarios, académicos y egresados entrevistados no cuestiona esta ideología y retoma en su totalidad la lógica de las licenciaturas interculturales. Permanece la pregunta práctica si los jóvenes profesionistas con vocación "alternativa" serán capaces de impulsar cambios significativos en sus entornos si sus almae matres los dotaron de una formación axiológica a medias que no enfrenta abiertamente las relaciones asimétricas imperantes en la sociedad y que se limita a hablar de una interculturalidad basada en la igualdad, respeto y diálogo que reduce los problemas sociales a una serie de asuntos de cultura. 


\section{Conclusiones}

La Universidad Intercultural mexicana es un modelo educativo emergente que reacciona a una realidad social sensible marcada por las diferencias culturales, exclusión social, pobreza y efectos más bien negativos de la globalización.

Las instancias oficiales mexicanas presentan la fundación de las Universidades Interculturales como un gran avance en el diálogo equitativo entre las culturas presentes en el país. No obstante, ante tales afirmaciones no hay que caer en la trampa del discurso plausible. Sin duda alguna, las Universidades Interculturales resultan ser una buena opción para los llamados culturalmente "otros" (indígenas) que desean incluirse en la sociedad mayoritaria en condiciones dignas, sin la humillación y represión identitaria que muy probablemente vivirían en una escuela de tipo convencional. Pero al mismo tiempo, hay que tener presente que el modelo educativo no es del todo transparente en cuanto a su ideología. Cuando las Universidades Interculturales atienden sus objetivos explícitos, principalmente el diálogo de saberes para la revalorización, desarrollo y "rescate" de las culturas originarias, simultáneamente cumplen con sus objetivos subyacentes que llamamos neoindigenistas: la negación de la autonomía étnica, integración paulatina del continuum de la realidad indígena en el sistema hegemónico existente (con énfasis en el mercado) y la reproducción de las relaciones de poder actuales. A diferencia del pasado no muy lejano, ya no se habla abiertamente de la inclusión de los pueblos originarios en un estado nación homogéneo; en cambio, se acude a una nueva retórica interculturalista que argumenta con su inserción en el mercado libre y su capacidad de competir existosamente en él.

En este contexto, aunque, sin duda, hay mucho que agradecer a la labor de la UNICH y la UIEM, al mismo tiempo es indispensable hacerles crítica para llamar la atención sobre la tarea pendiente de decolonizar incluso las instituciones autodenominanadas "interculturales". Es un paso necesario para formular propuestas encaminadas hacia los horizontes hasta la fecha no reconocidos como posibilidades reales, tales como la actuación autónoma de los grupos étnicos en el campo de la educación de su propia juventud.

(Escrito en español por la autora)

\section{BIBLIOGRAFÍA}

Aprender en sabiduría y el Buen Vivir, Quito: Universidad Intercultural Amawtay Wasi, 2004.

ÁVILA ROMERO, Agustín - ÁVILA ROMERO, León Enrique, "Las universidades interculturales de México en la encrucijada", Nóesis 50 (25), Ciudad Juárez: Universidad Autónoma de Ciudad Juárez, 2016, pp. 200-215.

ÁVILA ROMERO, León Enrique - BETANCOURT POSADA, Alberto - ARIAS HERNÁNDEZ, Gabriela - ÁVILA ROMERO, Agustín, "Vinculación comunitaria y diálogo de saberes en la educación superior intercultural en México", RMIE 70 (21), México: Consejo Mexicano de Investigación Educativa, 2016, pp. 759-783.

ÁVILA ROMERO, Agustín - ÁVILA ROMERO, León Enrique, "El asalto a la interculturalidad: las universidades interculturales de México”, Diversa 76 (27), México: Universidad Autónoma Metropolitana Unidad Xochimilco, 2014, pp. 37-54. 
CASILLAS MUÑOZ, María - SANTINI VILLAR, Laura, Universidad intercultural: un modelo educativo, México: SEP, 2006.

CASTRO-GÓMEZ, Santiago - GROSFOGUEL, Ramón, "Giro decolonial, teoría crítica y pensamiento heterárquico", in: Santiago Castro-Gómez - Ramón Grosfoguel (comps.), El giro decolonial: reflexiones para una diversidad epistémica más allá del capitalismo global, Bogotá: Siglo del Hombre Editores, 2007, pp. 9-24.

KORSBAEK, Leif - SÁMANO RENTERÍA, Miguel Ángel, "El indigenismo en México. Antecedentes y actualidad”, Ra Ximhai 1 (3), México: Universidad Autónoma Intercultural de Sinaloa, 2007, pp. 195-224.

LLANES ORTIZ, Genner, "Interculturalización fallida. Desarrollismo, neoindigenismo y Universidad Intercultural en Yucatán, México", Trace 53, México: Centro de Estudios Mexicanos y Centroamericanos, 2008, [consultado 20 de septiembre de 2010], Accesible de: http://trace.revues.org/index390. html.

ORTELLI, Paola - SARTORELLO, Stefano, "Jóvenes universitarios y conflicto intercultural. Estudiantes indígenas y mestizos en San Cristóbal de Las Casas, Chiapas”, Perfiles Educativos No. especial XXXIII, México: Instituto de Investigaciones sobre la Universidad y la Educación, 2011, pp. 115-128.

PARRA, Yolanda, "Para una pedagogía del Buen Vivir. Más allá del Océano: otros horizontes pedagógicos posibles,” in: Stefano Sartorello - León Ávila - Agustín Ávila (coords.), El Buen Vivir: Miradas desde adentro de Chiapas, San Cristóbal de las Casas: UNICH/IESALC/UNESCO, 2012, pp. 164-196.

\section{Breve información sobre la autora}

Zuzana Erdösová es doctora en estudios iberoamericanos de UAEMéx y doctora en lenguas romances de UPOL. Trabaja como profesora investigadora de tiempo completo en el centro de investigación en Ciencias sociales y Humanas de la Universidad Autónoma del Estado de México. Sus líneas de investigación versan sobre la interculturalidad, educación y lenguaje y la interculturalidad checo-mexicana. 